\title{
Evaluation of the Setting of the Global Promotion of the Czech Republic Destination
}

\author{
Sylvie Kotíková1,*, Karolina Pavlů $^{2}$ \\ ${ }^{1}$ Technical University of Liberec, Faculty of Economics, Department of Economics, 461 17, Liberec, \\ Studentská 1402/2, Czech Republic \\ ${ }^{2}$ Technical University of Liberec, Faculty of Economics, Department of marketing and business, 461 \\ 17, Liberec, Studentská 1402/2, Czech Republi
}

\begin{abstract}
Internationalisation is an increasingly common strategy for all types of companies across sectors, especially for tourism and destination management. The paper aims to evaluate the effectiveness of the current setting of marketing promotion of selected economies in the global market. The cost benefit analysis method compares the costs of individual international campaigns with the benefits measured by the number of arriving tourists from each target market. The costs and benefits of the internationalisation of the Czech Republic's marketing strategy (based on the CzechTourism data evidence) are subsequently quantified per unit, or how much money was needed to attract one tourist (given the cultural distance between economies) and the total amount of consumer spending of the tourist with the relevant source economy. The analyses showed paradoxically the low efficiency of the international campaign in Austria and Slovakia which, due to the amount of money spent, could not attract enough tourists. The net benefits of these promotions are EUR 74.84 for Austria and EUR 96.52 for Slovakia. On the other hand, the most effective was the campaign in Russia, which brought EUR 301.08 net profit. Marketing campaigns in India and the USA, where net profit exceeded EUR 200, can be considered successful.
\end{abstract}

\section{Introduction}

The theory of internationalization provides a way to explain and predict why and how company boundaries stretch across national borders [1,2]. Based on Coase [3], it is proposed that the international growth of multinationals be guided by the costs and benefits of internalising markets abroad. The main principles of the theory are: firms are profit maximisers in a world of imperfect markets; enterprises have an incentive to create internal markets to avoid imperfect external markets for intermediates owned or controlled by the firm. When internationalising a company, it faces several critical decisions, such as where and how much to invest, and how to organise and manage a foreign business to maximise benefits and minimise risks and losses. Theories of internationalisation explaining these processes and strategies are at the heart of international trade [4].

\footnotetext{
*Corresponding author: sylvie.kotikova@tul.cz
} 
To better understand the nature and impact of cross-border conditions, international business scientists have introduced the concept of distance (i.e. difference between countries) and applied it to a wide range of topics. Distance has been found to affect different organisational processes and results in multinationals, including location selection, input mode, standardisation procedures, knowledge transfer, performance, and more. The centrality of this condition has led some to conclude that "essentially international management is distance management" [5].

\section{Internationalization process}

The expansion of activities and processes abroad is much more demanding than in the domestic environment. Abroad, businesses face difficulties and incur additional costs as a result of political and economic risks in the host country as well as challenges to legitimacy. This is due to the lack of familiarity with the host country and the ways in which business is organised and managed, limited information on the opportunities and risks associated with operating in a foreign country, lack of adequate organisational skills to deal with these risks and common discrimination by local entities against "foreign" entities.

Theories of internationalisation of position selection are divided into two main types. The first is rooted in the economic tradition and the choice of a particular location for foreign investment is based on a rational decision-making process based on a set of clear criteria [6]. The second perspective takes a behavioural approach. It is based on Penrose [7] and emphasises the gradual learning that happens in internationalised firms, which in turn broadens the horizons of firms for future internationalisation [8].

\subsection{Cultural distance and its impact on internationalisation processes}

Cultural distance, i.e. the difference between the cultures of home and host countries, is an important factor in internationalisation strategies. In internationalisation processes, expansion initially takes place in culturally and/or geographically close countries and gradually reaches culturally and geographically more distant countries, learning from their international experience. The implicit idea here is that cultural distance creates difficulties and challenges for economic operators (actors), because lack of knowledge and understanding of how the host country works, as well as the perceived "stranger" or "psychic distance", which creates obstacles to cooperation [9]. Cultural distance affects all stages of the internationalisation process, including the pre-investment phase, when players have to decide whether to invest in a particular market, what input mode to use and how much to invest, as well as the post-investment phase, where the decision revolves around the degree of integration of a foreign site through common practices, as well as the performance of international investment [10].

Although the individual arguments about the impact of cultural distance vary according to degree and decision, the overarching reason is that cultural distance leads to higher complexity and the cost of doing business abroad. In theory, site selection studies usually explain the decision to extend to a specific host country based on the anticipated costs of communication, coordination and control. Therefore, they predict that actors will first seek countries (localities) that are culturally close and may later move to more distant countries. Another arguments are emphasising costs and economic aspects [11].

Some recent research is evidence of the limitations of this prediction as companies seem to be motivated to enter culturally (and otherwise) distant host markets due to their strategic and economic attractiveness. [12].

In this respect, it would be interesting to address the question of which culturally near or distant markets are targeted by tourism campaigns, and at the same time evaluate how cultural 
distance translates into success, respectively economic evaluation of these internationalisation actions.

Cultural distance is a concept measuring the extent to which consumers' origin cultures are different from or similar to the culture of the host [13]. Cultural distance can be treated as an alternative construct to explore culturally driven preferences and behaviour. Anecdotal and empirical evidence suggests that cultural distance affects tourists' destination choice.

\subsection{Cultural distance in tourism}

Culture has long been regarded as a possible reason to explain why people of different countries make decisions differently. Along with the globalisation of tourism economies, national culture has been incorporated as a key variable in an increasing number of tourism research studies [14]. These studies have attempted to reveal how culture accounts for tourist preferences and behaviours. Methodologically, a typical approach would be that individuals from different countries are surveyed, and variances in responses are ascribed to differences in cultural values.

Anecdotal and empirical evidences suggest that cultural distance affects tourists' destination choice. For example, the Pacific Asia Travel Association [15] suggested mainland China was the most popular destination for Hong Kong nationals because of similarity in cultural background. Giang et al. [16] noted that Australian tourists' intention to visit an overseas destination was negatively correlated with cultural distance. Philips et al. [17] have recently verified the existence of a cultural affinity effect in tourists' overseas destination choice. Specifically, tourists have a propensity to travel to regions with a shared cultural identity. It seems that empirical evidence suggests that tourists are more likely to travel to destinations with cultural similarity or low cultural distance [18]

Observations that run contrary to this proposition have also been made. McKercher and du Cros [19], for instance, found in their research that people from more culturally distant places were more likely to be motivated to travel for cultural reasons and seek deeper experiences. As noted earlier by Cohen [20], the desires for variety, novelty, and strangeness, the primary motives of tourism, could be better satisfied by larger cultural differences between traveller's cultural background and that of a destination. Past studies also suggest cultural distance may influence tourists' destination choice as cultural distance can interplay with travel motivations. Generally, the greater the cultural distance, the more possibly the potential tourists feel the destination can promise rich and unique culture, heritage, and history [18].

\section{Methods}

Information about incoming tourism and external marketing activities was obtained based on the open data of the CzechTourism [21] government agency. As the basic scientific method we chose cost-benefit analysis, reflecting: Marketing promotion costs by countries of world regions in 2018; Number of arriving tourists by country of world region in 2018. From these figures, the cost of attracting one tourist from the country was calculated as $n\left(C_{n}\right)$ :

$$
C_{n}=\frac{P R \cos t s_{n}}{T_{n}}
$$

Where, $P R \operatorname{costs}_{n}$ represents the cost of PR activities in the country $n$ and $T_{n}$ represents the number of tourists from country $n$ who visited the Czech Republic in 2018.

For a more comprehensive evaluation of the benefits of realised marketing campaigns, the average amount spent in the Czech Republic for the whole stay was calculated. $\left(A V S_{n}\right)$ : 


$$
A V S_{n}=\left(S_{n}-S B T\right) * D
$$

Where, the average expenses $\left(S_{n}\right)$ that a tourist from country $n$ actually spends in the Czech Republic i.e. excluding expenses before travel ( $S B T)$, such as airfare, insurance, etc., are multiplied by the number of days (D) actually spent by a country $n$ tourist on average.

Equation (1) represents costs per tourist and Equation (2) represents benefits per tourist. The final balance of the cost-benefit analysis is therefore the difference between the two values $\left(N B_{n}\right)$ :

$$
N B_{n}=A V S_{n}-C_{n}
$$

The cost-benefit analysis evaluates the prompt response to the marketing activities. The chosen approach reflects the effects of internationalisation promotion in a very short period. The evaluation of the long-term effect of promotion in 2018 will be possible at a longer time horizon, preferably in 2020. The added value of the chosen approach is not only calculation per unit, i.e. implementation of evaluation not only of the economic power of marketing events but also of their level. At the same time, the presented methodology, which takes into account the territorial aspect, compares and evaluates the effectiveness of the funds spent according to individual countries.

\section{Results of the cost-benefit analysis}

Most of the marketing promotion of the Czech Republic destination is managed by the CzechTourism agency. Its promotional activities can be divided into four regions - the Czech Republic, Central Europe, the rest of Europe and the rest of the world. Most marketing campaigns are organised in Central Europe and the rest of Europe, with CZK 522,104,364 for the Central European region and CZK 1,013,724,348 for the rest being spent on these campaigns (see Table 1 for more details). The highest internationalisation actions in terms of investment take place in culturally and geographically close areas. It is interesting that CzechTourism does not carry out any marketing activities in Africa. However, this can be attributed to the low market potential and the lack of purchasing power in comparison with other areas. For the Americas, it is represented only in the United States, where campaigns are conducted in other countries on the continent.

Table 1: classification by PR costs

\begin{tabular}{|l|l|}
\hline $\begin{array}{c}\text { PR costs in } \\
\text { CZK }\end{array}$ & Country \\
\hline $1-10$ mil. & Switzerland, India \\
\hline $10-25$ mil. & Mexico, Russia, Central and South America \\
\hline $25-50$ mil. & Scandinavia \\
\hline $50-100$ mil. & Benelux, Brazil, Slovakia, Spain, France, China \\
\hline $\begin{array}{l}100 \text { and more } \\
\text { mil. }\end{array}$ & $\begin{array}{l}\text { Austria, USA, Great Britain and Ireland, Germany, Japan, South Korea, } \\
\text { Hong Kong, Italy }\end{array}$ \\
\hline
\end{tabular}

Source: own processing based on data of CzechTourism

From an economic point of view, marketing campaigns were further divided into five groups according to the costs incurred. The largest number is represented in campaigns with more than one hundred million CZK spent. In this group we also find most Central European countries - Germany and Austria, which are closest to the Czech Republic. The smallest campaign was in the range of 25-50 million CZK; it was used only in Scandinavia. 
The last division was according to the incoming tourists to the Czech Republic destination. The number of tourists arriving from India is very interesting, which is included in the group of 50-100 thousand tourists, because only CZK 8 million was spent on promotion in the country, and this campaign attracted nearly 100,000 tourists (see Table 2).

Table 2: Number of arriving tourists

\begin{tabular}{|l|l|}
\hline Departures & Source country \\
\hline $1-50$ thousand & Saudi Arabia, UAE, Mexico \\
\hline $50-100$ thousand & Brazil, Central and South America, Canada, India, Australia \\
\hline $100-200$ thousand & Japan, Hong Kong, Israel, Switzerland \\
\hline $200-500$ thousand & Benelux, Scandinavia, France, Spain, Italy, Austria, South Korea \\
\hline 500 thousand and more & $\begin{array}{l}\text { USA, Russia, Germany, Slovakia, Poland and the Baltic States, } \\
\text { China }\end{array}$ \\
\hline
\end{tabular}

Source: own processing based on data of CzechTourism

Arrivals of tourists from the Arabian Peninsula are also interesting, as there was no targeted campaign in the area, but the destination of the Czech Republic was introduced only at trade fairs, namely in Saudi Arabia at the fair in Riyadh, and in the UAE the Czech Republic was introduced at ATM Dubai and then in cooperation with other V4 countries at the Discover Central Europe roadshow. Altogether more than 60 thousand tourists came to Czechia from these two states.

Table 3: Results of the cost benefit analysis

\begin{tabular}{|c|c|c|c|c|c|c|c|}
\hline Country & $\begin{array}{c}\text { Number of } \\
\text { tourists }\end{array}$ & PR costs & $\mathbf{C}_{\mathbf{n}}(\mathbf{1})$ & $\begin{array}{c}\text { Spends } \\
\text { per day }\end{array}$ & Days & $\begin{array}{c}\mathbf{A V S}_{\mathbf{n}} \\
(\mathbf{2})\end{array}$ & $\mathbf{N B}_{\mathbf{n}}(\mathbf{3})$ \\
\hline Germany & $2,033,065$ & $222,022,467$ & 109.206 & 1,284 & 3.9 & $5,007.6$ & $4,898.394$ \\
\hline Slovakia & 734,910 & $58,926,105$ & 80.181 & 831 & 3.0 & 2,493 & $2,412.819$ \\
\hline Austria & 299,162 & $241,155,792$ & 806.104 & 923 & 2.9 & $2,676.7$ & $1,870.596$ \\
\hline Italy & 409,903 & $279,117,725$ & 680.936 & 1,226 & 3.7 & $4,536.2$ & $3,855.264$ \\
\hline Spain & 267,487 & $61,197,784$ & 228.788 & 1,300 & 3.7 & 4,810 & $4,581.212$ \\
\hline France & 287,129 & $69,736,892$ & 242.877 & 1,312 & 3.5 & 4,592 & $4,349.123$ \\
\hline $\begin{array}{c}\text { GB and } \\
\text { Ireland }\end{array}$ & 554,374 & $223,874,344$ & 403.833 & 1,386 & 3.6 & $4,989.6$ & $4,585.767$ \\
\hline USA & 555,736 & $120,869,906$ & 217.495 & 1,713 & 3.5 & $5,995.5$ & 5778.005 \\
\hline India & 96,325 & $8,098,043$ & 84.070 & 1903 & 3.5 & $6,660.5$ & $6,576.43$ \\
\hline China & 619,877 & $84,791,984$ & 136.788 & 2180.7 & 2.5 & $5,451.75$ & $5,314.962$ \\
\hline $\begin{array}{c}\text { South } \\
\text { Korea }\end{array}$ & 416,243 & $138,773,712$ & 333.396 & 1822.86 & 2.6 & $4,739.44$ & $4,406.04$ \\
\hline Russia & 545,406 & $23,648,282$ & 43.359 & 1,402 & 5.4 & $7,570.8$ & $7,527.441$ \\
\hline Poland & 728,554 & $272,085,206$ & 373.459 & 870 & 3.1 & 2,697 & $2,323.541$ \\
\hline
\end{tabular}

Source: own calculation based on data from CzechTourism

The analyses showed low efficiency of the international campaign in Austria and Slovakia, which could not attract a sufficient number of tourists due to the amount of money spent. The net benefits of these promotions are CZK 1,871 for Austria and CZK 2,413 for Slovakia. On the other hand, the most effective campaign was in Russia, which brought CZK 7,527 of net profit. Marketing campaigns in India and the USA, with net profit exceeding CZK 5,000, can be considered very successful. In the case of Austria, CZK 241,155,792 was spent on marketing activities, and CZK 23,648,282 was spent on a campaign in Russia. 


\section{Discussion and conclusion}

In terms of costs, the largest internationalisation events take place in culturally close localities. These findings fully correspond to the claims [11, 18]. It has been confirmed that cultural proximity plays a role, particularly in the case of the impact of marketing promotion in Russia, when both markets are connected by similar language and history, as in the case of Germany, where this market is a neighbouring country to the Czech Republic, therefore, there is an identifiable geographical proximity, including cultural proximity, as both countries are linked in terms of historical events and often family ties. However, this was not confirmed in the case of Austria. The net benefit from promotional activities (3) in this market was only $1,800 \mathrm{CZK}$. There is a similar situation in Slovakia, where the net benefit was less than CZK 2,000.

On the other hand, the claim that one of the main motives for travelling is to experience something new is also confirmed. This is true in the case of the success of promotional campaigns in China and South Korea or even in India, where many tourists were attracted from these countries and the net benefits of these campaigns were in all cases higher than four thousand Czech crowns. Specifically, in the case of China, the net benefit of the campaigns is approximately CZK 5,300, for South Korea CZK 4,400 and for India CZK 6,600. It can therefore be stated that the more demanding internationalisation actions in culturally distant markets have borne fruit in terms of market benefits [12].

In these cases, however, it can be taken into account that these tourists do not stay on our territory for a long time - an average of 2.5 days - and the destinations of their visits are Prague and Český Krumlov, as a UNESCO monument (which lies on the route to neighbouring Austria). It cannot therefore be unequivocally confirmed that in the field of tourism it is worthwhile to focus on nearby markets and not on remote ones with companies wishing to internationalise.

The benefit of the research lies not only in the presented findings but also in the chosen methodology of calculating the so-called Net contribution of marketing campaigns quantified per capita, reflecting the level and efficiency of invested funds by country. The results are beneficial for CzechTourism and, of course, for economic operators in the field of tourism who can better modify the focus of their marketing activities in relation to the countries with the highest traffic. The current limit of research is the evaluation of only short-term (immediate) effects. However, this limit represents the future focus of the research, when it will be possible to draw conclusions about the impact of marketing campaigns in the long term in a few years.

The acknowledgement: The paper was processed under the SGS grant Evaluation of the influence of foreign capital holders in the business environment

\section{References}

1. Buckley, P. J., \& Casson, M. C., The future of the multinational enterprise (London: Macmillan 1976)

2. M. Castano, Innovation, internationalization and business-growth expectations among entrepreneurs in the services sector. Journal of Business research, 69(5), 16901695 (2016)

3. R. Coase, The nature of the firm. Economica, 4(4), 386-405 (1937)

4. V. Marano, J. L. Arregle, M. A. Hitt, E. Spadafora, M. van Essen, Home country institutions and the internationalization-performance relationship: A meta-analytic review. Journal of Management, 42(5), 1075-1110 (2016) 
5. A. Mohr, G. Batsakis, Z. Stone, Explaining the effect of rapid internationalization on horizontal foreign divestment in the retail sector: An extended Penrosean perspective, $J$ Int Bus Stu, 49 (2018)

6. S. Beugelsdijk, B. Ambos, P.C. Nell, Conceptualizing and measuring distance in international business research: Recurring questions and best practice guidelines, $J$ Int Bus Stud, 49 (2018)

7. E. Penrose, The theory of the growth of the firm (Oxford: Oxford University Press, 1959)

8. B. Marco-Lajara, Tourist districts and internationalization of hotel firms. Tourist Management, 61, 451-464 (2017)

9. Y. Chandra, A time-based process model of international enterpreneurial opportunity evaluation, J Int Bus Stud, 48 (2017)

10. S. Mingo, F. Morales, The interplay of national distances and regional networks: Private equity investments in emerging markets L.A. Dau, J Int Bus Stud, 49 (2018)

11. B. Esiyok, The effect of Cultural distance on medical tourism. Journal of Destination Marketing \& Management, 6(1), 66-75 (2017)

12. J. Bi, Ch. Gu, Cultural distance and international tourists' intention to visit a destination. Asia Pacific Journal Of Tourism Research, 24 (8) 839-849 (2019)

13. Ch. Wang, A. Varma, Cultural distance and expatriate failure rates: the moderating role of expatriate management practices. International Journal of Human Resource Management, 30(15), 2211-2230 (2019)

14. L. Watkins, J. Gnoth, The value orientation approach tounderstanding culture. Annals of Tourism Research, 38(4), 1274-1299 (2011)

15. Pacific Asia Travel Association (PATA), Tracking Asian outboundtravel trends.Travel Industry Monitor, 63 (1995)

16. M. Qiang, M. Shen, H. Xie, Cultural diffusion and international inbound tourism: evidence from China, Tourism Economics, Tourism Economics, 10.1177/1354816618811211 (2018)

17. P. Phillips, N. Antonio, A. de Almeida, L. Nunes, The Influence of Geographic and Psychic Distance on Online Hotel Ratings, Journal of Travel Research, 10.1177/0047287519858400, (2019)

18. J. Bi, X. Lehto, Impact of cultural distance on international destination choices: The case of Chinese outbound travelers. International Journal of Tourism Research, 20(1), 50-59 (2018)

19. B. McKercher, H. du Cros, Testing a cultural tourism typology. International Journal of Tourism Research, 5(1), 45-58 (2003).

20. E. Cohen, Toward a sociology of international tourism. Social Research, 39(1), 164182 (1972). 